\title{
AWARE in West Antarctica \\ Clouds, climate, and critical ice melt
}

\author{
Adapted from "AWARE: \\ The Atmospheric Radiation \\ Measurement (ARM) \\ West Antarctic Radiation \\ Experiment," by Dan Lubin \\ (Scripps Institution of \\ Oceanography), Damao \\ Zhang, Israel Silber, Ryan \\ C. Scott, Petros Kalogeras, \\ Alessandro Battaglia, David \\ H. Bromwich, Maria Cadeddu, \\ Edwin Eloranta, Ann Fridlind, \\ Amanda Frossard, Keith \\ M. Hines, Stefan Kneifel, \\ W. Richard Leaitch, Wuyin Lin, \\ Julien Nicolas, Heath Powers, \\ Patricia K. Quinn, Penny Rowe, \\ Lynn M. Russell, Sangeeta \\ Sharma, Johannes Verlinde, \\ and Andrew M. Vogelmann. \\ Published online in BAMS, \\ July 2020. For the full, citable \\ article, see DOI:10.1175/BAMS \\ -D-18-0278.1.
}

apid climate change on the West Antarctic Ice Sheet (WAIS) has challenged previous explanations of Antarctic climate change that focused on strengthening of circumpolar westerlies. A recent study linked surface melting conditions on the WAIS to atmospheric blocking over the Amundsen Sea region and to a negative phase of the southern annular mode, both of which correlate with El Niño in the tropical Pacific.

There is a need to quantify the role of these changing air masses in the surface energy balance (SEB), and to improve the accuracy of global climate model simulations, which tend to perform poorly over the Antarctic and the Southern Ocean. The relative scarcity of cloud information at southern high latitudes has also inhibited progress.

Surface melt during summer is important in WAIS mass loss-which is closely tied to global sea 


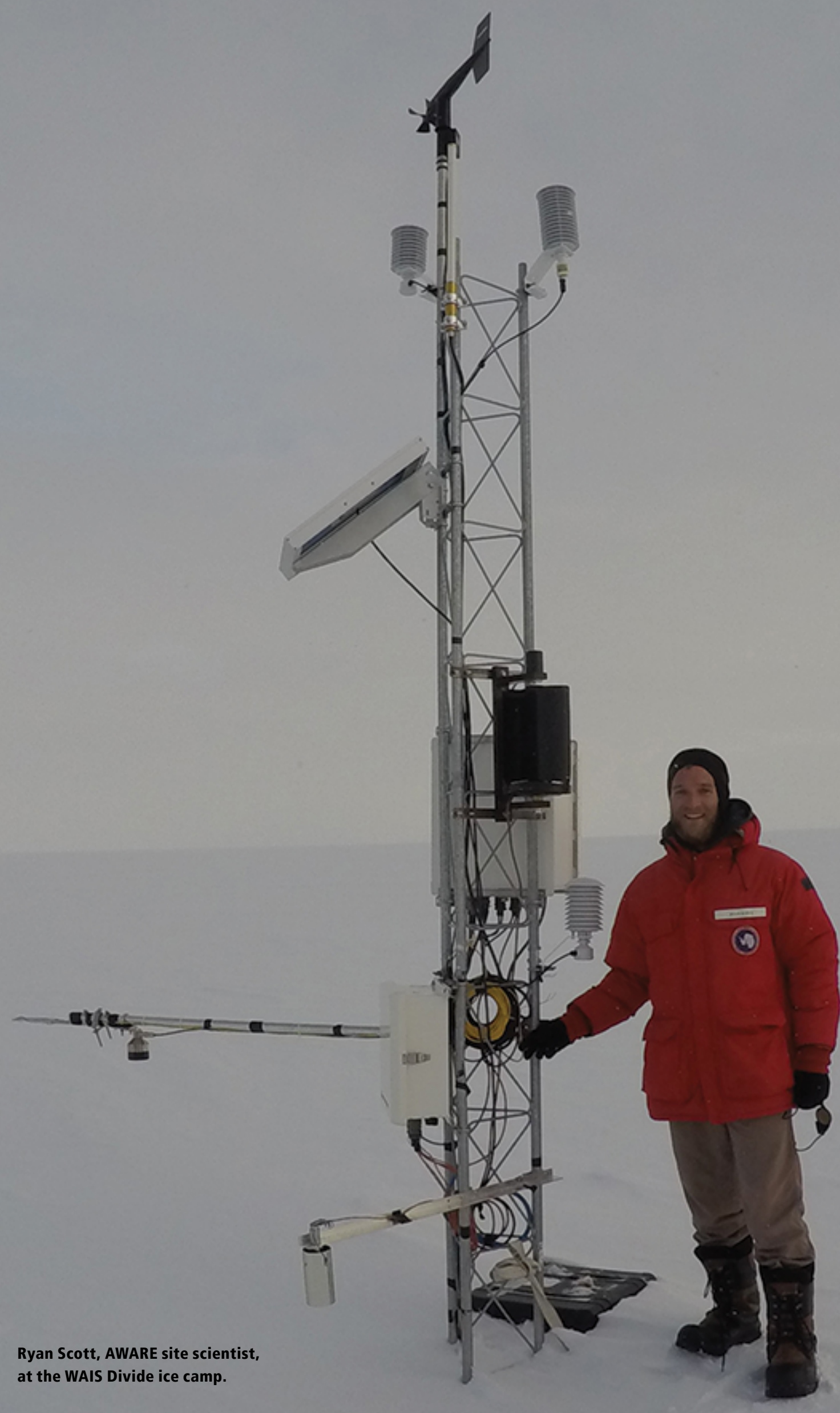



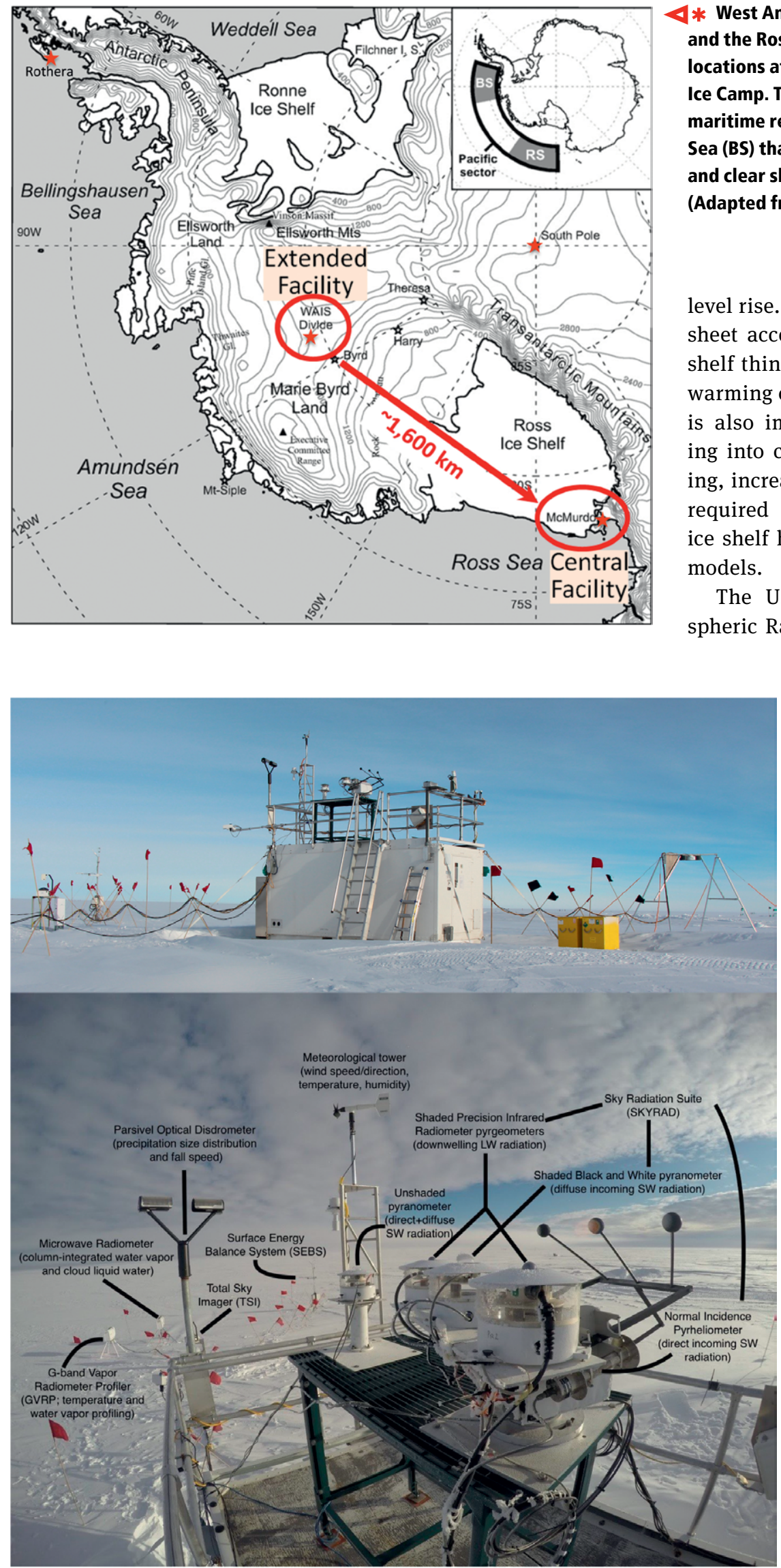

4 * West Antarctica, the Transantarctic Mountains, and the Ross Ice Shelf, with AWARE measurement locations at McMurdo Station and the WAIS Divide Ice Camp. The insert at the upper right indicates maritime regions Ross Sea (RS) and Bellingshausen Sea (BS) that influence moisture advection/cloud and clear skies over West Antarctica, respectively. (Adapted from Nicolas and Bromwich 2011).

level rise. The largest immediate cause of ice sheet acceleration in West Antarctica is ice shelf thinning via melting at its base from a warming ocean. Direct atmospheric warming is also important. Surface meltwater filtering into crevasses can induce hydrofracturing, increasing calving. Actual field data are required to improve parameterizations for ice shelf hydrofracturing in coupled climate models.

The U.S. Department of Energy Atmospheric Radiation Measurement (ARM) West Antarctic Radiation Experiment (AWARE) acquired a full year's data critical to understanding atmospheric forcing on West Antarctica and to fostering related improvements to climate model performance. A suite of cloud research radars, lidars, radiometers, aerosol chemical and microphysical sampling equipment, and meteorological instrumentation was deployed at McMurdo Station on Ross Island from December 2015 through December 2016. A smaller suite of radiometers and meteorological equipment (including radiosondes), optimized for surface energy budget measurement,

\section{$4 *$ The AWARE surface energy} budget equipment at WAIS Divide. (top) View of the sea container housing most of the instruments, with the SKYRAD installation at the far right and Total Sky Imager, ceilometer, and surface turbulent flux instruments at the far left. (bottom) Detail of the instrument installation on the roof of the sea container. 
was flown to the West Antarctic Ice Sheet and operated between 4 December 2015 and 17 January 2016. This represented the first permanent installation of atmospheric or climate science instrumentation beyond automated weather stations.

\section{Arctic comparisons}

These installations provided Antarctic atmospheric data comparable to several wellinstrumented high Arctic sites that have operated for many years. Due to AWARE, we see many contrasts with the high Arctic in aerosol

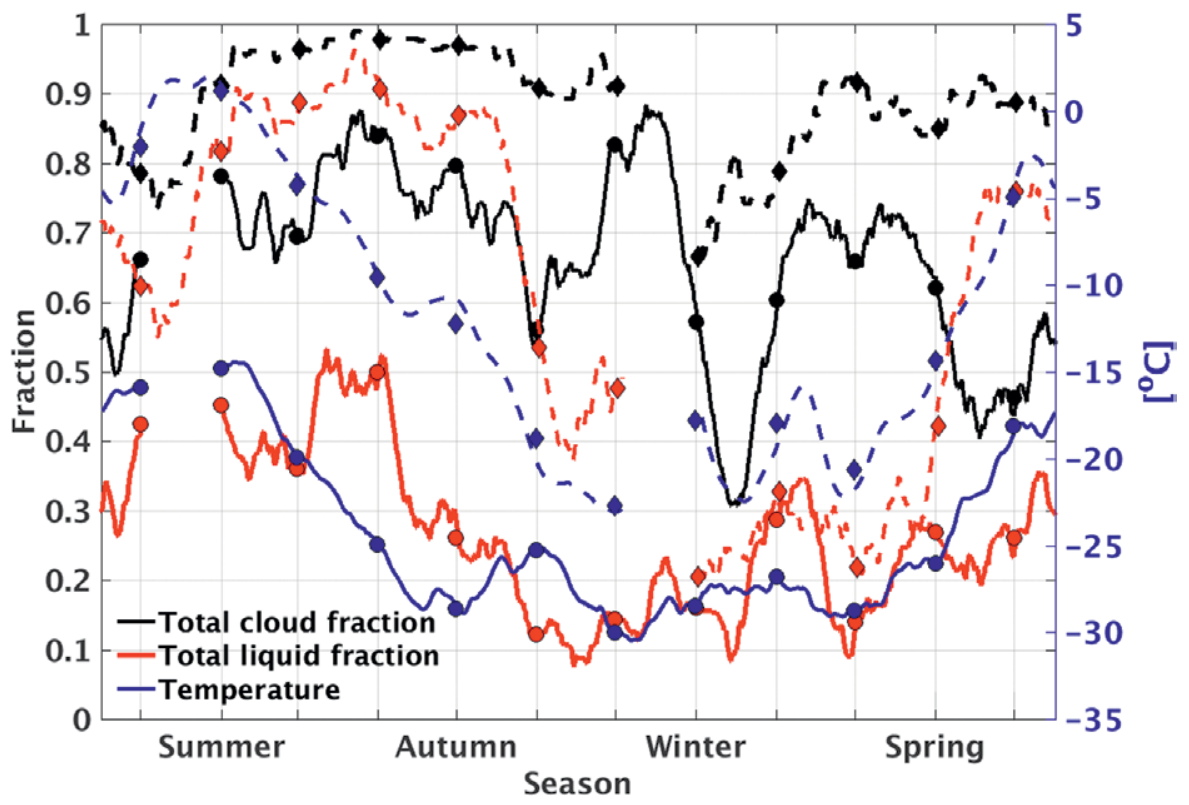
and cloud microphysical properties. For example, the Arctic radiation budget is strongly influenced by persistent and long-lived mixed-phase clouds, whereas the more varied influences on Antarctic clouds often yield markedly different manifestations of mixed-phase cloud microphysics. These include persistent differences in liquid cloud occurrence, cloud height, and cloud thickness. For example, most clouds are thicker at McMurdo, but the deepest, likely frontal, clouds are observed in the Arctic. The observed cloud-top heights and temperatures are more variable in the Arctic. Specific cases indicate that at McMurdo, clouds are optically thinner overall, and liquid droplets typically have smaller effective radii. Growth processes such as aggregation and riming are important in snow production-related processes in Antarctica-at least where moisture is sufficient, such as close to the coast. In general, West Antarctica is highly susceptible to advection of warm and moist maritime air, with related cloud cover.

Antarctic aerosol properties are also quite different from the Arctic in both seasonal cycle and composition, due to the continent's isolation from lower latitudes by Southern Ocean storm tracks. Aerosol concentrations in Antarctica reflect a seasonal cycle in which abundances are almost entirely from a variety of Antarctic sources-of ocean phytoplankton, seabirds, sea spray, and non-sea salt dustrather than transported sources. By contrast,

$\Delta$ * The ARM North Slope of Alaska (NSA) facility at Utqiagivik in Alaska, adjacent to the Beaufort Sea, is an Arctic maritime location with variable sea ice concentration. Instrumentation at the NSA site is very similar to the ARM mobile facility (AMF2) deployed at McMurdo, which serves as the basis for comparison of the clouds and aerosols of the two polar climates. For example, the annual hydrometeor occurrence fraction is higher by $\mathbf{2 0} \%$ at Utqiagivik-and the liquid occurrence fraction by $31 \%$-than at McMurdo. This is depicted by the 30-day (+1-h) running-mean total hydrometeor and liquid-cloud occurrence fractions at McMurdo (solid) and Utqiagivik (dashed). The monthly mean values are given by the filled markers. The months represented in each season here for McMurdo and Utqiagivik are DJF (JJA in the Arctic) for summer, MAM (SON in the Arctic) for autumn, JJA (DJF in the Arctic) for winter, and SON (MAM in the Arctic) for spring. The temperature curve (based on sounding profiles) represents the average temperature between the surface and 4-km altitude. The $x$ axis ticks mark the sixteenth of each month at 0000 UTC.

in the Arctic, springtime haze results from transport from the northern midlatitudes. Both biogenic and organic non-sea salt sulfate sources can affect cloud droplet number concentrations in Antarctica, potentially increasing cloud drop effective radius and shortwave reflection. 


\section{Climate modeling applications}

The AWARE campaign's first major result came from the WAIS Divide, in a significant West Antarctic melt event in January 2016 associated with a strong El Niño year. An abrupt warming at the WAIS Divide on 10 January was largely due to a blocking high-pressure ridge advecting warm marine air toward West Antarctica. The warmth remained through 20 January. The unusual extent and duration made this melt event one of the greatest observed in the Ross Ice Shelf in the satellite era. The rapid lower troposphere warming and moistening provides a unique case study for climate models.

Simulations by the Polar Weather Research and Forecasting regional model (PWRF), a high-latitude adaptation of the WRF model, failed to capture the relatively high liquid water content in this melt event. Early on 10 January, little cloud liquid water is simulated, and possibly as a result, the simulations are several degrees too cold.

Two global climate models under development also used the WAIS Divide melt event as a case study. These models overestimated the liquid water path of the supercooled clouds, with important consequences for the amount of energy in the snowpack. These case results show AWARE data can help attribute model biases.

\section{Future work}

AWARE data may have limitations-for example, as applied to high terrain areas of East Antarctica. Also, the project trailed a large El Niño, and the data might therefore be representative of warmer than normal conditions. However, the project showed Antarctic aerosol number and mass concentrations are not only nonnegligible but perhaps are more important than previously recognized because of the higher sensitivities of clouds at the very low concentrations caused by the large-scale dynamical isolation. AWARE results imply that aerosol-cloud interaction in the Antarctic deserves further study.

Although separated by $1,600 \mathrm{~km}$, the two AWARE sites are often meteorologically related. Low-pressure troughs in the Ross Sea frequently bring moisture and cloud cover over the WAIS that eventually reach Ross Island after substantial orographic lifting and related ice cloud formation. Tracking these synoptic-scale patterns might provide further

\section{The AMF2 installation at the McMurdo Station CosRay site. (top) View of the entire site showing locations of adjacent meteorological and radar calibration target towers, and the southerly view of the scanning radars. (bottom) Detail of instrument installation within the AMF2. $\frac{*}{\nabla}$}

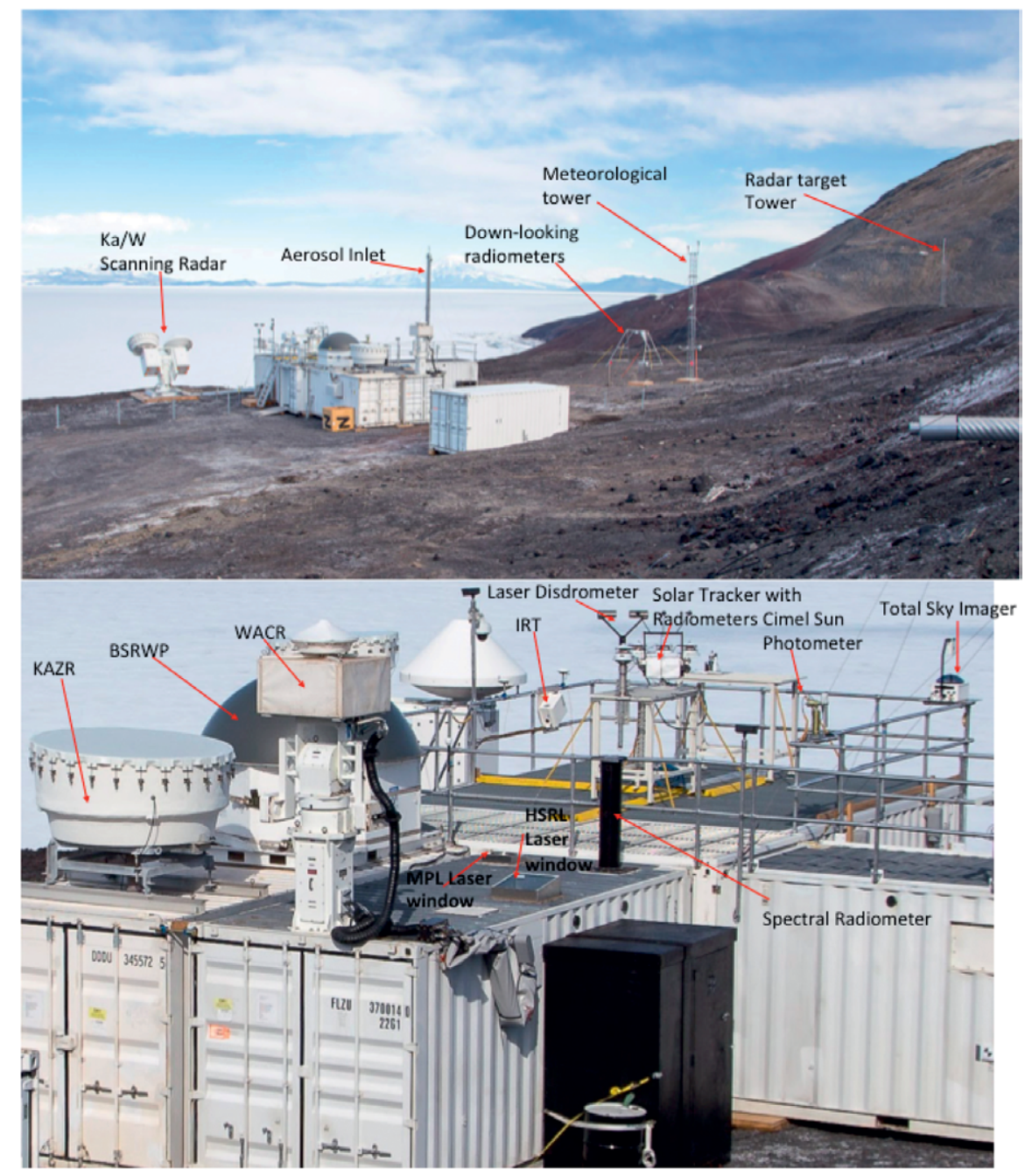


insight into Antarctica's mixed-phase cloud properties.

Much work needs to be done on cloud microphysical parameterizations or other model components to improve model performance over Antarctica. The AWARE dataset, fully available online in the ARM program data archive, offers numerous case studies for these purposes.

\section{” METADATA}

BAMS: What would you like readers to learn from this article?

\section{Dan Lubin (Scripps Institution of Oceanography): While the major} mechanisms for Antarctic ice sheet loss related to sea level rise involve oceanic warming under ice shelves and at the ice sheet grounding line, the atmosphere can be expected to play an increasing role in a warming climate, particularly over the floating ice shelves that buttress the ice sheets behind them and which are vulnerable to degradation by surface melt water. At the same time, the atmosphere over Antarctica is very different from the atmosphere over the Arctic. The high terrain near the coast and near ice shelves exerts unique dynamical influences on mixedphase clouds. Case studies from AWARE data can provide stringent tests of climate model parameterizations. We also found that Antarctic aerosol composition and seasonal variability is influenced by a variety of interesting natural sources-some unexpected-so going forward with research we can expect regional variability and unique aerosol-cloud interactions.

BAMS: How did you become interested in Antarctic research fieldwork?

DL: After I finished my undergraduate physics degree from Northwestern I was looking for something that might be adventurous, and wasn't even fully considering graduate school. But just down the street, in the Department of Geophysical Sciences at the University of Chicago, I learned that there were opportunities to go to Antarctica. So I applied and then did my Ph.D. work on the Antarctic ozone "hole" at Palmer Station. I've stayed interested in polar atmospheric science for more than 30 years because there has always been something new to work on. The enormous logistical challenges in Antarctica ultimately mean that a successful field program can have a big scientific impact.

BAMS: What surprised you the most in this experiment?

DL: I was surprised at how well the DOE equipment performed in the extremely harsh environments of West Antarctica and winter on Ross Island. I had high confidence for a generally successful program, given my prior experience with the ARM Program. But from my own prior experience I expected that some systems might not work or might fail early in the campaign. Yet during AWARE every major instrument worked for at least a few months, and most lasted throughout the year.

BAMS: Were there any instruments in particular that posed a problem?

DL: I was also a little worried about the aerosol component, because its deployment site was a bit of a compromise, near a main road with traffic from heavy vehicles. I was surprised by how well that contamination could be filtered, giving us a full year of very interesting data.

BAMS: What was the biggest challenge you encountered while doing this work?
DL: Designing a field campaign that is directly relevant to the most pressing climate change issue. Ideally we want to be at a location where the action is, like Thwaites or Pine Island Glacier. That was logistically impossible. The closest we could get, where there was the minimum necessary power and infrastructure, was the WAIS Divide Ice Camp. Even there, we had to bring all our equipment and personnel in a single LC-130 flight from McMurdo Station. And we had to wait three weeks for the weather to clear to make that flight. McMurdo was the only place on the continent that could support the full ARM Mobile Facility. Fortunately there are enough meteorological factors in common across the Ross and Amundsen/Bellingshausen Sea regions that many of the findings from Ross Island are relevant to West Antarctica as well.

BAMS: What's next? How will you follow up?

DL: We have already done a follow-on campaign supported by NSF. We've been working on miniaturizing some of the key surface energy balance and spectroscopic equipment so it can be operated with solar power alone. In December 2019 through January 2020 we deployed these new instruments at Siple Dome, a very small summer field camp in West Antarctica at a lower elevation than WAIS Divide. This gave us another interesting case study involving mixed-phase clouds. 


\section{Be prepared, not scared.}

ret scare 1
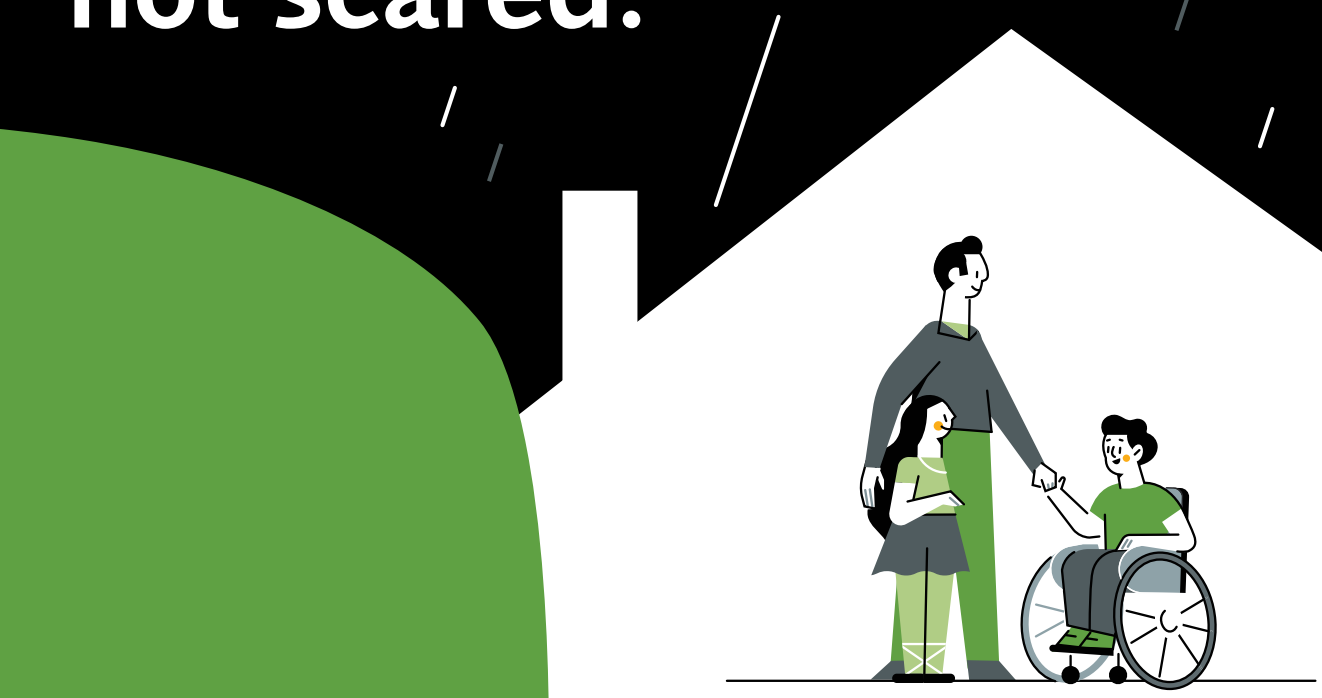

Considering the number of disasters that have occurred in the past decade, chances are you'll experience some sort of emergency. Between school, sports and other activities, chances are you won't be with your kids when it happens.

Ready.gov/kids has the tools to make preparing easy and even fun, so your kids can feel...

Prepared, not scared.

\section{Go to \\ www.Ready.gov/kids} and talk to your family today.

Ready. FEMA 